\title{
The Examination of Muscle Balance in Dancers
}

\author{
Kovácsné Bobály Viktoria ${ }^{1, *}$, Makai Alekszandra ${ }^{1}$, Kiss Gabriella ${ }^{2}$, Szilágyi Brigitta $^{2}$, Ács Pongrác $^{2}$, \\ Jaromi Melinda ${ }^{2}$ \\ ${ }^{1}$ School of Health Sciences, University of Pecs, Hungary \\ ${ }^{2}$ Faculty of Health Sciences, Institute of Physiotherapy and Sports Science, University of Pecs, Hungary
}

Copyright $(2016$ by authors, all rights reserved. Authors agree that this article remains permanently open access under the terms of the Creative Commons Attribution License 4.0 International License

\begin{abstract}
The aim was to examine the anthropometric parameters of representatives of different dance styles, the strength and extensibility of trunk muscles, and whether low back pain influences performance during a show or stage appearance. According to our hypothesis, low back pain and deviations in the functional conditions of the spine are common in dancers aged 9-18, and can have a negative effect in their performance on stage. In addition, we assume that weakness can be experienced in the strength of the trunk muscles, their extensibility is not appropriate even in spite of regular training. 92 dancers (average age: $14,15 \pm 2,95$ years) participated in the examination: 30 ballet dancers, 32 ballroom dancers, and 30 hip-hop dancers. The anthropometric data was measured with OMRON KaradaScan body composition monitor, the level of the negative effect of low back pain on stage performance was measured by visual analogue scale, and the strength and extensibility was measured with a Kraus-Weber test. On the basis of the anthropologic evaluation, we received a significant difference concerning each examined parameters (body weight: $p=0,000$, height: $p=0,000$, muscle mass: $p=$ 0,001 , BMI: $p=0,000$, body fat percentage: $p=0,000$ ), the reason of which was the fact that the different dance styles have different physical requirements for the dancers. In accordance with data measured by the visual analogue scale, no significant difference was received $(p=0,104)$ between the examined groups, although the hip-hop dancers reported the highest percentage $(10,54 \%)$ of the occurrence of low back pain that negatively affects their stage performance. On the basis of the Kraus-Weber test, in the case of both abdominal muscle exercises the hip-hop group had significantly better performance (K-W A.: $p=0,016, K-W$ B.: $p=0,001)$ than the other two groups. Concerning muscle extensibility, (K-W F.: $p=0,030$ ) the ballet group had significantly better results. In the case of all three examined groups it can be claimed that despite regular training, low back complaints occur at a very young age, which also have negative effects on stage performance.
\end{abstract}

Keywords Dance, Low Back Pain, Stage Performance, Trunk Muscles, Muscle Balance

\section{Introduction}

The different dance styles have different physical requirement for dancers, however, the basis of each style is the classical ballet. Among professional dancers, if a form of musculoskeletal condition occurs during their career, then the treatment thereof must be adjusted to the given dance style. [1]

According to Hungarian research, one of the most common complaints is low back pain, which more typically occurs in adulthood, but affects professional dancers as early as during their dance studies. In most cases this is caused by the degenerative deformities of intervertebral discs, and the decreasing of the intervertebral gap, and dislocations in smaller joints. Low back pain is often caused by twisting movements, turns, landing from jumps. [2] International publications state that dancers often suffer from low back pain. The main reason thereof is that different dance styles often require extreme lumbar extensions, or permanently applied, intensive lumbar lordosis position. In the course of this, however, neuromuscular alterations occur in the affected areas, which can cause frequent sensations of pain. In addition, these positions have a negative effect on habitual posture, due to the long-set lordotic position. In latest research, we have encountered aspirations that specifically deal with the restoration of these deformities among dancers. [3]

The majority of the publications indicate a higher frequency in the occurrence of low back complaints and injuries in female dancers. In the study by Alderson and Co. the authors claim that these injuries occur in a significantly higher number in the case of male ballet dancers than in their female counterparts, which is likely to be the consequence of performing lifting moves. This study examines vertebrae L5 and S1, and the forces affecting the joints thereof, in 5 professional and 3 semi-professional dancers, through arabesque lifts and full press lifts. With the help of a 3 dimensional movement analysis system, they found that the largest shearing force affects the frontal third of the vertebrae 
located towards the abdomen (,static weak point”, PLASFpeak lumbar anterior shear), as the female ballet dancer takes a vertical position during the lifting move, thus placing approximate compression forces on the vertebrae of her partner.

8 male ( $22+-6$ years) and 3 female ( $26+-10$ years) dancers participated in the examination, from Australian dance academies. During the examination 54 markers were placed on the back of the body, on limbs, trunk and head of the male dancers, in accordance with the marker model of UWA, and with the help of these, received a 3 dimensional image of the complete body structure. On female dancers, 6 markers were placed along the hip bone, and 2 on the legs, in order to examine the forces affecting the body in the moment of jumping. 12 cameras recorded all movements, and the Workstation software, while automatically remodelling these, compared the forces with the 3 dimensional movement patterns.

The examinations showed that the strength of shearing and compression forces affecting the spine is nearly 3400 , thus the examiners decided to observe the dancers more frequently, and as a result, the risk of back pains resulting from lifting moves decreased among the dancers. The results also indicated that full press lifting moves pose larger compression on the low back of male dancers than arabesque lifting moves. [4]

In addition to strict physical demands and requirements concerning the physique of dancers different dance styles often need dancers to be able to perform a range of motion wider that the physiological movement of the spine. $[5,6]$ The motion range of the cervical section of the spine and of the head is 50-60 degrees, however, in the case of certain dance styles, such as classical ballet, contemporary modern dance and ballroom dance, the range is wider, especially the turning of the head, which can be 75-85 decrees, besides, in the case of the spine, a motion range suitable for more flexible, larger-scale movements is typical. [7]

If we consider the occurrence of injuries according to dance styles, then, the study of Smith and Co. noted that ballet dancers are the most frequently injured dancers. Injuries occurring during the career of 2617 ballet dancers were listed, and the data indicated that $51 \%$ of muscle injuries occurred on the trunk, $14 \%$ of which led to chronic low back pain. [8]

The muscular causes of low back pain include muscle imbalance and the deconditioned state of the muscles. A sedentary lifestyle, one-sided strain, or training, or pain can lead to muscle imbalance. The concept of muscle imbalance is associated with Lewit, Janda and Sachse, who elaborated the system of operation of striated muscles. According to Lewit, Janda and Sachse, the first system of operation includes muscles that are likely to be subject to hypertonia, shortening, such as the sternal section of $\mathrm{m}$. pectoralis major, the upper section of the $\mathrm{m}$. trapesius, the lumbar section of the $\mathrm{m}$. erector spinae, and the hip flexors. The muscles belonging to the second operational unit tend to weaken, overstretch, such as the $\mathrm{m}$ gluteus maximus, the abdominal muscles, the lower and middle sections of the $\mathrm{m}$. trapesius, and the $\mathrm{m}$ rhomboideus. Due to the shortening of the $\mathrm{m}$. pectoralis major pars sternalis and the upper section of the $\mathrm{m}$. trapesius, and to the weakening of the $\mathrm{m}$. rhomboideus and the lower and middle sections of the $\mathrm{m}$. trapesius, the shoulder is affected by protraction, and the thoracialis kyphosis increases. Due to the shortening of the lower section of the $\mathrm{m}$. erector spinae, the shortening of the hip flexors, and the weakening of the abdominal and gluteal muscles, the angle of the pelvis changes, and the lumbar lordosis increases. As a result of the shortening and weakening, overstretching of these muscles, the posture, and also the position of the median and centre of gravity changes, the strain increases on the joints and intervertebral disc. $[9$, 10]

Muscle decondition occurs as a result of the inactivity of the musculoskeletal system, which can lead to pain. Pain results in further inactivity, the avoidance of strain and movement, and thus the chronic pain cycle is created. In a chronic pain cycle, the metabolism and function of tissues are damaged. This process affects ligaments, muscles, cartilage covering the surface of joints, intervertebral discs, joint capsules, bones. The functional capacity and motion range of the lumbar spine decreases, resulting in decrease in the strength and endurance of the synergistic muscles that ensure movement and stability, which leads to the functional disorder of the muscle system affecting the neuromuscular system with regard to coordination and proprioception. [11, 12]

\subsection{The Aim of the Research}

The aim is to study the anthropometric data of dancers and the conditions of trunk muscles from the aspect of muscle balance. We wished to study to what extent does the occurring low back pain influences the performance of dancers on stage.

\subsection{Research Questions, Hypotheses}

It is assumed that the anthropometric data of dancers pursuing different dance styles are also different.

It is assumed that low back pain has a negative effect on theatrical performance of dancers.

It is assumed that the strength of muscles necessary for the stability of the spine and essential in preventing spine injuries (core muscles) is weak.

It is assumed that the extensibility of the muscles that are important for the health of the spine is not appropriate.

\section{Materials and Methods}

\subsection{Examination Sample}

Our sample includes representatives from 3 dance styles $(\mathrm{n}=92$, average age: $14,15 \pm 2,95$ (9-24) years). Our 
examination groups consist of one classic ballet group $(n=30$, average age: $12,7 \pm 2,18$ (9-19) years), one hip-hop group $(\mathrm{n}=30$, average age: $13,7 \pm 2,88(9-24)$ years), and one ballroom dance group ( $\mathrm{n}=32$, average age: $15,8 \pm 2,87$ (10-22) years). The ballet dancers have been dancing for an average of 4,5 $\pm 2,51$ (e. v.:1-10) years, with $3 \pm 1,06$ (e.v.:2-6) (pcs) training sessions per week where the length of training session is an average of $96 \pm 12,2$ minutes (e. v.: $90-120$ ), and have an average number of $1,3 \pm 1,68$ (e. v.: (0-10) (pcs), performances monthly, with a length of $35,1 \pm 26,11$ minutes (e. v..: 0-120). The members of the ballroom dance group

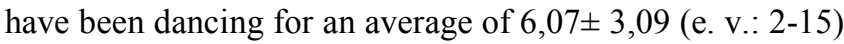
years, with $3,5 \pm 0,98$ (e. v.: 2-5) (pcs) training sessions per week, each training is of the length of $90 \pm 0,00$ (e. v.: 90-90)

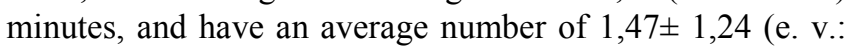
$0-4$ ) (pcs), performances monthly, with a length of $24,03 \pm$ 21,54 (e. v.: 0-120) minutes. The hip-hop dancers have been dancing for an average of 5,03 $\pm 3,13$ (e. v.: 2-14) year, work with an average number of training sessions per week of $2,43 \pm 0,69$ (e. v.: 2-5) (pcs), where the length of the trainings is an average of $115,71 \pm 45,25$ (e. v.: 60-180) minutes, complemented by an average number of $1,68 \pm 0,67$ (e. v.: $0-3)$ (pcs), performances monthly, with a length of $44,82 \pm$ 27,77 (e. v.: 0-120) minutes. It is characteristic of the whole sample, that, despite their young age, the examined dancers have been dancing for an average of 5,22 $\pm 2,97$ (e. v.: 1-15) years, with an average number of $3,02 \pm 1,02$ (e. v.: 2-6) weekly trainings, where the length of the training sessions is $100 \pm 28,08$ (e. v.:60-180) minutes on average. In addition to the regular weekly trainings, they have an average monthly number of $1,49 \pm 1,27$ (e. v.: 0-10) (pcs), 34,21 $\pm 26,28$ (e. v.: 0-120) minutes long performances.

\subsection{Selection Criteria}

A minimum of three years of regular dancer background at a given company or school.

\subsection{Exclusion Criteria}

A spine condition that requires treatment, spine surgery, sports injury in the last 3 months, participation in trunk prevention programme in the last six months.

\subsection{The location of the Examination}

Institution of Physiotherapy and Sport Science, University of Pécs, Faculty of Health Science (7623 Pécs, 4. Rét Street.) Classic Ballet dance group: Pécs Secondary School of Art, Dance Specialization (7624 Pécs, 9 Radnics Street.)

Ballroom dance group: Kapronczai Elementary Institution of Art Education (7900 Szigetvár, 73/1 Széchenyi Street.)

Hip-hop group: Tamás Dance Leisure Sport and Dance Association (7636 Pécs, 11. Tildy Zoltán Street)

\subsection{Research Methodology}

\subsubsection{Anthropometric test}

In anthropometric examination the height, weight, muscle mass, body fat percentage, and BMI (Body Mass Index) was determined with OMRON KaradaScan type (E-BODY-12/201312-03489F) body composition monitor.

\subsubsection{Examination of the intensity of low back pain}

The intensity of the low back pain was examined with the help of visual analogue scales. The participants marked the intensity of the low back pain in accordance with their own judgement, on a 100-grade scale, between $0-100 \%$, in respect of the extent the low back pain influenced their performance during a show or on stage. $0 \%$ means that it does not influence them in the case in the question, $100 \%$ means it has a large influence on it. [13]

\subsubsection{Muscle balance examination}

Kraus-Weber test: The test consisted of six exercises, 0-10 points could be received for each exercise, each of which was marked separately, and was also evaluated on the basis of the total number of points $(0-60)$.

K-W A.: The subject lies flat on their back, pressing the lumbar section of the spine on the floor, and, with legs kept straight, lifts both legs to $30^{\circ}$

Evaluation: If the subject is able to keep the position for 10 seconds, they receive 10 points. If the spine is lifted off the floor, or the legs drop, the test is over.

K-W B.: The subject lies flat on their back, their hands behind the neck, and performs one sit-up while the legs are held on the floor by a helper.

Evaluation: The complete sit-up is 10 points, performing half of the sit-up is 5 points, and failure to perform the test is 0 point.

K-W C.: The subject lies on their back, with their hands behind the neck, and performs one sit-up while their knees are bent and ankles are close to the buttock.

Evaluation: The complete sit-up is 10 points, performing half of the sit-up is 5 points, and failure to perform the test is 0 point.

K-W D.: The subject lies on their stomach, with hands behind the neck, then they lift their trunk off the floor and keep the position for 10 seconds.

Evaluation: 1 point for every second of keeping the position, with a maximum of 10 points.

K-W E.: The subject lies on their stomach, with the hands behind the neck, and, keeping the leg straight and ankles together, lifts their legs and keeps the position for 10 seconds.

Evaluation: 1 point for every second of keeping the position, with a maximum of 10 points.

K-W F.: The subject stands up straight, then bends forward, and keeps the position.

Evaluation: 10 points for reaching the floor, if not, then the distance between the fingertips and the floor is measured, and one point is deducted for every $2.5 \mathrm{~cm}$.

Total: If the total of points reaches a value between 50 and 60 , then the test is considered good, between $0-40$, it is considered weak. [14, 15] 
Table 1. Anthropometric data

\begin{tabular}{|c|c|c|c|c|c|c|c|c|c|}
\hline \multicolumn{10}{|c|}{ Anthropometric test } \\
\hline \multirow{2}{*}{$\begin{array}{l}\text { Examined } \\
\text { parameters }\end{array}$} & \multicolumn{2}{|c|}{ Ballet } & \multicolumn{2}{|c|}{ Ballroom dance } & \multicolumn{2}{|c|}{ Hip-hop } & \multicolumn{2}{|c|}{ Total } & \multirow{2}{*}{$\frac{\text { Difference }}{\text { p-value }}$} \\
\hline & Mean value & $\begin{array}{c}\text { Stand. } \\
\text { dev. }\end{array}$ & Mean value & $\begin{array}{c}\text { Stand. } \\
\text { dev. }\end{array}$ & Mean value & $\begin{array}{c}\text { Stand. } \\
\text { dev. }\end{array}$ & Mean value & $\begin{array}{c}\text { Stand. } \\
\text { dev. }\end{array}$ & \\
\hline Height $(\mathrm{cm})$ & 155,417 & 8,449 & 169,313 & 11,423 & 157,929 & 8,187 & 161,139 & 11,285 & 0,000 \\
\hline Weight (kg) & 43,350 & 8,991 & 59,934 & 14,474 & 52,793 & 12,979 & 52,184 & 14,087 & 0,000 \\
\hline $\begin{array}{c}\text { Muscle mass } \\
(\%)\end{array}$ & 34,677 & 2,313 & 37,041 & 5,605 & 32,461 & 3,134 & 34,828 & 4,381 & 0,001 \\
\hline $\begin{array}{c}\text { Body fat } \\
\text { percentage }\end{array}$ & 17,690 & 6,010 & 19,372 & 7,757 & 26,089 & 9,037 & 20,901 & 8,384 & 0,000 \\
\hline BMI & 17,647 & 2,229 & 20,563 & 3,318 & 20,650 & 3,854 & 19,618 & 3,454 & 0,000 \\
\hline \multirow{2}{*}{$\begin{array}{l}\text { Examined } \\
\text { parameters }\end{array}$} & \multicolumn{2}{|c|}{ Ballet } & \multicolumn{2}{|c|}{ Ballroom dance } & \multicolumn{2}{|c|}{ Hip-hop } & \multicolumn{2}{|c|}{ Total } & Difference \\
\hline & Mean value & Stand. dev. & Mean value & Stand. dev. & Mean value & Stand. dev. & Mean value & Stand. dev. & p-value \\
\hline VAS & 3,000 & 5,509 & 10,000 & 17,039 & 10,536 & 14,551 & 7,833 & 13,679 & 0,104 \\
\hline
\end{tabular}

\subsection{Applied Statistical Methods}

The SPSS 20.0. programme was used for the evaluation of the received results, and the average value and standard deviation for each examined parameter was thus calculated. All variables in the complete sample were subjected to a normality test with the Kolmogorov-Smirnov test, on the basis of which it could not be considered a normal distribution, thus non-parameter tests were performed. The three groups were compared with Kurskal Wails test concerning each examined parameter. The level of significance was determined in each case at the value $\mathrm{p}<0,05$.

\section{Results}

\subsection{Results of the Anthropometric Examination}

Significant difference was found concerning every examined parameter in respect of the anthropometric data. The values received indicate that the three highly different dance styles require different physical attributes from their pursuers. With regard to height, ballroom dancers proved to be significantly taller $(p=0,000)$, than ballet dancers and hip-hop dancers. Concerning muscle mass, a significantly higher value was also measured in the case of the ballroom dance group $(p=0,001)$. With regard to weight, BMI and body fat percentage, a significantly lower value was measured in the case of ballet dancers $(p=0,000$ for all three parameters) than in the case of the members of the other two examined groups. (Table 1)

\subsection{Examination Results Concerning the Intensity of Low Back Pain}

Relations between low back pain and training load:

The first point of the scale (VAS1) concerned whether pain influenced performance on stage, and no significant difference was detected here $(p=0,104)$, but again, the members of the hip-hop group reported the existence of the pain in the highest number $(10,54 \%)$. (Table 2$)$

\subsection{Examination of Muscle Balance}

According to the integrated result of $\mathrm{KW}$, the dancers' muscle balance is appropriate, but from the trunk muscles, the abdominal muscle group performed averagely $75,7 \%$, the back muscle group performed averagely $97,8 \%$ of the strength tests. In addition the dancers, in different dance styles showed other differences in the muscle group strength tests and extensibility tests. 
Table 3. Examination of trunk muscle strength and extensibility with Kraus-Weber test

\begin{tabular}{|c|c|c|c|c|c|c|c|c|c|}
\hline \multicolumn{10}{|c|}{ Muscle balance examination with Kraus-Weber test } \\
\hline \multirow[b]{2}{*}{ Examined parameters } & \multicolumn{2}{|c|}{ Ballet } & \multicolumn{2}{|c|}{ Ballroom dance } & \multicolumn{2}{|c|}{ Hip-hop } & \multicolumn{2}{|c|}{ Total } & \multirow{2}{*}{$\begin{array}{r}\text { Differenc } \\
\text { p-value }\end{array}$} \\
\hline & $\begin{array}{l}\text { Mean } \\
\text { value }\end{array}$ & $\begin{array}{c}\text { Stand. } \\
\text { dev. }\end{array}$ & $\begin{array}{l}\text { Mean } \\
\text { value }\end{array}$ & $\begin{array}{c}\text { Stand. } \\
\text { dev. }\end{array}$ & $\begin{array}{l}\text { Mean } \\
\text { value }\end{array}$ & $\begin{array}{c}\text { Stand. } \\
\text { dev. }\end{array}$ & $\begin{array}{l}\text { Mean } \\
\text { value }\end{array}$ & $\begin{array}{c}\text { Stand. } \\
\text { dev. }\end{array}$ & \\
\hline Kraus-W. A. & 7,433 & 3,720 & 9,531 & 1,481 & 9,107 & 1,950 & 8,700 & 2,696 & 0,016 \\
\hline Kraus-W. B. & 9,167 & 1,895 & 9,219 & 1,845 & 7,321 & 2,539 & 8,611 & 2,252 & 0,001 \\
\hline Kraus-W. C. & 7,000 & 2,491 & 7,500 & 2,540 & 7,679 & 2,539 & 7,389 & 2,512 & 0,561 \\
\hline Kraus-W. D. & 9,833 & 0,913 & 9,688 & 1,230 & 10,000 & 0,000 & 9,833 & 0,903 & 0,409 \\
\hline Kraus-W. E. & 9,333 & 1,729 & 10,000 & 0,000 & 9,643 & 1,311 & 9,667 & 1,254 & 0,111 \\
\hline Kraus-W. F. & 9,700 & 1,643 & 8,738 & 2,955 & 7,625 & 4,169 & 8,712 & 3,146 & 0,030 \\
\hline Kraus-W. Total & 52,467 & 8,585 & 54,831 & 4,652 & 51,196 & 7,129 & 52,912 & 7,021 & 0,140 \\
\hline
\end{tabular}

Based on the totalized points of the Kraus-Weber test, no significant difference $(p=0,140)$ was found. However, in the case of the individual exercises, significant differences were discovered concerning different muscle groups. In the exercise concerning the strength of the abdominal muscle (Kraus-W. A.), significant difference was experienced $(p=0,016)$ between the three groups, where, according to the average points, the abdominal muscle strength of ballroom dancers was the highest and that of ballet dancers was the lowest. In the case of the second exercise (Kraus-W. B.), which was also aimed at the examination of abdominal muscle strength, there also was a significant difference $(p=0,001)$ between the three groups, where, yet again, the abdominal muscle strength of ballroom dancers was the highest, while that of the hip-hop dancers was the lowest. In the third exercise examining the strength of abdominal muscles (Kraus-W. C.) no significant difference was found $(p=0,561)$ a between the three groups, although on the basis of average values, the hip-hop group proved to be the best and the ballet dancers the worst. In the case of the fourth exercise, examining the strength of back muscles, (Kraus-W. D.) again, no significant differences were received $(p=0,409)$ between the groups, however, on the basis of the average values the hip-hop group had the best results, while the ballroom dancers had the worst. In the case of the fifth exercise of the test, also examining the muscle strength of back muscles, (Kraus-W. E.) no significant difference was discovered $(p=0,111)$, but on the basis of the received values, the muscle strength of ballroom dancers proved to be the highest, while that of ballet dancers was the lowest. The last exercise of the test (Kraus-W. F.) measured muscle extensibility, and in this case the ballet dancers had significantly better $(p=0,030)$ results than the other two examined groups. In extensibility, big differences were found between the groups, which tests were performed averagely $76,2-97 \%$. In point of extensibility ballet dancers got significantly better $(\mathrm{p}=0,030)$ result, than the other two test groups. (Table 3)

In summary, we can say, that our first two hypotheses totally, the third and fourth partly confirmed: Dancers in different dance styles have disparate anthropometric parameters.
Law back pain has a negative effect on dancers' theatrical performance.

According to Kraus-Weber test dancers have appropriate muscle balance, but in point of abdominal muscle strength we measured only $72,1 \%$ performance.

\section{Discussion}

\subsection{Anthropometric Data}

Based on each data received in the course of examining body composition, significant differences were discovered between the examined groups, which unambiguously show that the three different dance styles require completely different physical attributes from the dancers. In the respect of height, the ballroom dancers proved to be significantly taller than the representatives of the other two dance styles, and the same result was received concerning muscle mass, where the results of ballroom dancers were again higher. Concerning BMI, weight and body fat percentage, the values of the ballet dancers were significantly lower than those of the other two groups. Having studied international literature, several articles could be found which deal with the physique and anthropometric attributes of ballet dancers. [16]

Among the three groups, the ballet dancers' career imposes the strictest requirements concerning the physique of the dancers. The bodies of ballet dancers are strong and supple at the same time. Since the dancers continuously work with their legs, they need to be muscular and strong, as, for example during a full point tiptoe position, their whole body weight is supported by two toes of each foot. A raised instep is essential in addition to the ability of the potential dancer to twist their leg at the hip joint in 90 degrees. Strong and flexible Achilles tendon, long legs, short trunk, long neck and small round head are typical characteristics of ballet dancers. International examinations have determined an average $19,7 \pm 2,4 \mathrm{BMI}$ value in the case of adolescent female ballet dancers, and in the present study nearly identical value was measured $(17,64)$ is. [17] 


\subsection{Relationship between Low Back Pain and Training Load}

Examination of low back pain:

Based on the examination using the visual analogue scales (VAS) it can be observed that complaints related to low back pain occur at a relatively young age in the case of dancers, which also determines their performance at trainings and rehearsals, and occurs during and after trainings. Hip-hop dancers reported low back pain in the largest number, which they experience before and after stage performances, and which a large percentage of the dancers consider an influential factor on their performance during shows.

In literature among dancers Quinlan et al. examined 13 year old female dancers, whom have spinosus process apophysitis. Because of hyperextension, that cause law back pain in teen-age among dancers. [18] Regarding literature several author wrote about the high incidence of law back pain among dancers, that reason can be numberless. Some of them submit, that hyperextension, intensified lordotic posture, lack of lumbar motor control capability or intensified rotational motions cause it, however any of them lead to law back pain, or other lesions. [19, 20] Gottschlich et al. searched the frequency of injuries among dancers, which showed, that the second most common injured area is the trunk among professional dancers. It enumerated among the main complaints the hyperlordosis, spondylosis, lumbar facet sprain, discognetic back pain, muscle spasm and piriformis syndrome. [21] Hagins et al. made a questionnaire survey in point of law back pain with aid of Oswestry Disability Index. Examined 37 professional female dancer, during which made a 5 year retrospection in point of complaints and injuries, that leaded to loss of function and degenerative lesions in T12-L1 segment.

Each of the dancers reported that 5 months passed before the full functionality of the injured musculoskeletal segment recovered and the pain ceased completely. During the examinations, the dancers carried out spine stabilizer exercise programme, after which the initially measured $48 \%$ probability of injury dropped to $26 \%$. [22]

\subsection{Examination of Muscle Balance}

On the basis of the examination it can be observed that among the three examined groups, in the respect of the strength of abdominal and back muscles, the ballroom dancers had significantly better results than the other two examined groups. According to the accounts of their trainer, the reason presumably is that their training program, although not with accurate regularity, includes exercises which are aimed at strengthening the back and trunk muscles. Concerning muscle extensibility, as expected, ballet dancers had significantly better results than the representatives of the other two dance styles. The result thereof is that the classical ballet training contains several exercises that are specifically aimed at increasing muscle extensibility. Regarding literature, no studies can be found where dancers were examined with this method, although there are a number of them where the strength and extensibility of trunk muscles was examined in the case of non-dancer youths of similar age. $[23,24]$ However, literature includes examinations of the strength and extensibility of trunk muscles, carried out with a different method. Gildea and Co. performed muscle cross-section examination on ballet dancers with MRI concerning four muscle groups: m. multifidus, the lumbar section of the $\mathrm{m}$. erector spinae, $\mathrm{m}$. psoas major, $\mathrm{m}$. quadratus lumborum. The dancers were compared on the basis of three factors: dancers with low back and hip pain, dancers only with low back pain and dancers without low back and hip pain. The results showed that in the case of dancers not suffering from low back pain, the cross-section size of $\mathrm{m}$. multifidus is larger at the height of the L3-5 (lumbar section, 3rd 5th vertebrae) than that of dancers suffering from low back pain $(p=0.024)$. There is a difference in the size of the right- and left-side muscles, but there is no connection with the location of the pain (it is not the side with the smaller muscle that hurts). There is no difference between the groups concerning the other muscles. In the case of male dancers, the cross-section of muscles $\mathrm{m}$. psoas and the m. quadratum lumborum is larger than in the case of female dancers. Thus, ballet dancers suffering from low back and hip pain, the cross-section diameter of the $\mathrm{m}$. multifidus is smaller, but there is no difference in the respective sizes of the $m$. erector spinae and the $m$. quadratus lumborum. [25, 26]

\section{Conclusions}

Research proves concerning examinations conducted in several sports, that even with regular training, the static strength of muscles stabilizing the spine is lower, and that the extensibility of muscles essential for correct posture is not appropriate. Both in the case of athletes and dancers it can be observed that due to unbalanced training load, muscle imbalance can occur, as a result of which performance deteriorates pain can occur and injuries can happen.

It is now common among sportspeople to apply such core prevention exercise programmes like core-training or neuromuscular training. Due to these prevention programmes the intensity of low back pain decreases, the number of low back pain episodes drops, as the muscle imbalance that had formed because unbalanced training or incorrect posture decreases or ceases. Core prevention programmes include general and sport-specific components. The general component includes exercises improving the static trunk muscle strength. The sport-specific component practices the static and dynamic trunk muscle exercises through the special movement forms of the given sport or dance, and also improves lumbar motor control ability essential for correct posture and for the prevention of low back pain. Such prevention programme designed for dancers is the plank exercise sequence developed by Krauss and Co. which can easily be practised at home, ant for which a special 
strap has also been devised. The programme is based on strengthening the transverse abdominal muscles, which play a key role in correct posture and preventing chronic low back pain. [27] In their study Rickman and Co. also noted that among dancers, complaints and injuries affecting the spine occur with a high frequency, with an especially high percentage in the case of the low back area. Thus they recommended that the core stability programme consisting of exercises aimed at strengthening muscles essential for posture is applied in the case of professional dancers. [28] In the course of our research we also developed a program aimed at improving the strength and extensibility of trunk muscles, whose efficiency is currently being tested among dancers of Pécs. [29] The weekly application of these prevention programmes can play an essential role in preventing different spine injuries and chronic low back pain both in the case of amateur and professional dancers.

\section{REFERENCES}

[1] Mády F. Klasszikus balett-táncosok mozgásszervi elváltozásai. Kandidátusi értekezés. Budapest 1995.

[2] CupistiA, D'Alessandro C, Evangelisti I, Piazza M, Galetta F, Morelli E. Low back pain in competitive rhythmic gymnasts. The Journal of sports medicine and physical fitness; 2004; 44 (1):49-53.

[3] Smith J. Moving beyond the neutral spine: stabilizing the dancer with lumbar extension dysfunction. Journal of dance medicine and science; 2009; 13(3):73-82.

[4] Alderson J, Hopper L, Elliott B, Ackland T. Risk factors for lower back injuryin male dancers performing ballet lifts. Journal of dance medicine and science; 2009;13 (3):83-9.

[5] Bria S, Bianco M, Galvani C, Palmieri V, Zeppilli P, Faina M. Physiological characteristics of elite sport-dancers. The journal of sports medicine and physical fitness; 2011; 51(2):194-203.

[6] Hergenroeder AC, Brown B, Klish WJ. Anthropometric measurements and estimating body composition in ballet dancers. Medicine and science in sports and exercise; 1993; 25(1):145-50.

[7] Mády F. Mozgásbiológia és egészségtan, Magyar Táncművészeti Főiskola, Budapest; 2013

[8] Smith T, Davies L, Medicic A, Hakimd A, Haddadc F, Macgregora A. Prevalence and profile of musculoskeletal injuries in ballet dancers. Physical Therapy in Sport; 2016; 5(1); 51-57.

[9] Bálint G, Bender T. A fizioterápia elmélete és gyakorlata. Springer, Budapest, 1995; 67.

[10] Mannion AF, Taimelas S, Muntener M. Active therapy for chronic low back pain. Effects on back muscle activation, fatigability and strength. The Spine Journal; 2001; 26, 897-908.

[11] Balogh I. Mozgás ABC, Kineziológiai alapismeretek. Tillinger, Szentendre; 1999; 90-107.
[12] Ferenc M, Varga PP. Az ágyéki gerinc fúziós mütéte utáni aktív ágyéki stabilizáció. Mozgásterápia. 1998; 3. 2-6.

[13] Ogona M, Krismera M, Söllnerb W, Kantner-Rumplmairb W, LampebA. Chronic low back pain measurement with visual analogue scales in different settings. Pain; 1996; 64 (3):425-8.

[14] Ángyán L. Sportélettani vizsgálatok, Motio Kiadó Bt. Pécs, 1995.

[15] Babalola JF, Awolola OE, Hamzat TK. Reliability of Kraus-Weber exercise test as an evaluation tool in low back pain susceptibility among apparently Healthy University Students. African Journal for Physical, Health Education, Recreation and Dance; 2008; 14(2): 188-198.

[16] Liiv H, Wyon MA, Jürimäe T, Saar M, Mäestu J, Jürimäe J. Anthropometry, somatotypes, and aerobic power in ballet, contemporary dance, and dance sport. Medical problems of performing artists; 2013; 28 (4):207-11.

[17] Beck KL, Mitchell S, Foskett A, Conlon CA, von Hurst PR. Dietary intake, anthropometric characteristics, and iron and vitamin D status of female adolescent Ballet Dancers living in New Zealand. International journal of sport nutrition and exercise metabolism; 2015; 25 (4):335-43.

[18] Quinlan E, Reinke T, Bogar WC. Spinous process apophystis: a cause of low back pain following repetitive hyperextension in adolescent female dancer. Journal of Dance Medicine and Science; 2013; 17(4):170-4.

[19] Roussel N, de Kooning M, Schutt A, Mottram S, Truijen S, Njis J, Daenen L. Motor control and low back pain. International Journal of Sports Medicine; 2013; 34(2):138-43.

[20] Jenkins JB, Wyon M, Nevil A. Can turnout measurements be used to predict physiotherapist-reported injury rates in dancer? Medical Problems of Performing Artists; 2013; 28(4):230-5.

[21] Gottschlich LM, Young CC. Spine ijuries in dancers. Current Sports Medicine Reports; 2011; 10(1):40-4.

[22] Hagins M. The use of stabilization exercises and movement reeducation to manage pain and improve function in a dancer with focal degenerative joint disease of the spine. The use of stabilization exercises and movement reeducation to manage pain and improve function in a dancer with focal degenerative joint disease of the spine. Journal of Dance Medicine and Science; $2011 ; 15$ (3):136-42.

[23] Moreira RF, Akagi FH, Wun PY, Moriguchi CS, Sato TO. Effects of a school based exercise program on children's resistance and flexibility. Work; 2012; 41 (1):922-8.

[24] Okada T, Nakazato K, Iwai K, Tanabe M, et al. Body mass, nonspecific low back pain, and anatomical changes in the lumbar spine in judo athletes. Journal of orthopaedic and sports physical therapy; 2007; 37(11): 688-93.

[25] Gildea JE, Hides JA, Hodges PW. Size and symmetry of trunk muscles in ballet dancers with and without low back pain. The Journal of Orthopedic and Sports Physical Therapy; 2013; 43 (8):525-33.

[26] Simmons RW. Neuromuscular responses of trained ballet dancers to postural perturbations. The International Journal of Neuroscience; 2005; 115(8):1193-203.

[27] Kline JB, Krauss JR, Maher SF, Qu X. Core strength training 
using a combination of home exercises and a dynamic sling system for the management of low back pain in pre-professional ballet dancers: a case series. Journal of dance medicine and science; $2013 ; 17$ (1):24-33.

[28] Rickman AM, Ambegaonkar JP, Cortes N. Core stability: implications for dance injuries. Medical problems of performing artists; 2012; 27 (3):159-64.

[29] Kovacsne BV, Jaromi M. Törzsprevenciós mozgásprogram táncosoknak, Pécs; 2015 